\title{
ANTI-INFLUENZA ACTIVITY OF SEVERAL CARYOPHYLLANE THIOSESQUITERPENOIDS
}

\author{
Yu. V. Gyrdymova, ${ }^{1 *}$ E. O. Sinegubova, ${ }^{2}$ A. S. Muryleva, ${ }^{2}$ \\ V. V. Zarubaev, ${ }^{2}$ and S. A. Rubtsova ${ }^{1}$
}

Seasonal influenza is an acute respiratory infection caused by influenza viruses spreading over the whole world. Influenza virus A is responsible for most infections, including those with lethal outcomes. Treatments of patient infected with this type of virus are complicated by possible resistance to all existing drugs. This was most evident in 2007-2009 when an oseltamivir-resistant phenotype appeared among practically all virus subtype H1N1 isolates [1-3]. Natural compounds can act as promising antiviral agents. Several monoterpene derivatives are known to be active against influenza virus type A $[4,5]$. The only sesquiterpene with such activity is isocaryophyllene acetamide [6]. The anti-influenza activity of $S$-containing sesquiterpenoids has not been reported. Therefore, studies of the antiviral properties of sesquiterpenes containing $S$-groups are crucial and of indubitable practical interest.

The antioxidant and membrane-protective properties of thiosesquiterpenoids synthesized from caryophyllene oxide were studied earlier by us [7].

In continuation of research on the biological properties of thiosesquiterpenoids, we conducted primary screening of caryophyllane derivatives against the pandemic influenza virus strain A/Puerto Rico/8/34 (H1N1). Table 1 presents the results.

Table 1 shows that introducing $S$-containing functional groups into caryophyllene oxide (1) increased in most instances the antiviral properties and reduced the cytotoxicity as compared with starting $\mathbf{1}$. Thus, 4,5-epoxycaryophyllanyl-15-thiol (3), its vinyl thioether $\mathbf{5}$, symmetric disulfides $\mathbf{7}$ and $\mathbf{8}$, asymmetric disulfides with 2-aminophenyl- and 5-nitropyridine groups $\mathbf{1 1}$ and 12, and bis-sulfides 13 and $\mathbf{1 4}$ exhibited the greatest virus-inhibitory activity. The inhibitory properties of these molecules were diminished by a conjugated aromatic system in asymmetric disulfide $\mathbf{9}$ or an electron-donating substituent (MeO) in 10.
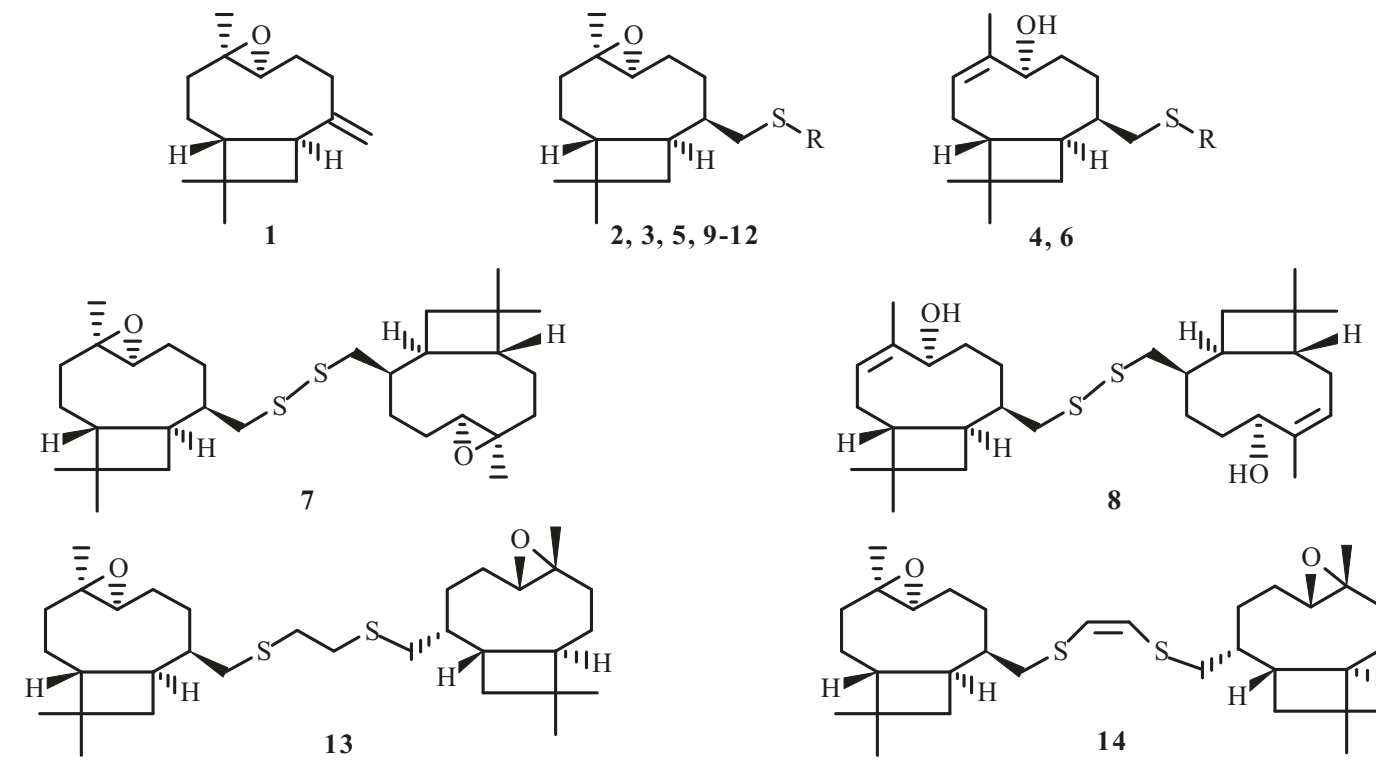

$\mathrm{R}=\mathrm{Ac}(\mathbf{2}) ; \mathrm{H}(\mathbf{3}, \mathbf{4}), \mathrm{CH}=\mathrm{CH}_{2}(\mathbf{5}, \mathbf{6})$; benzimidazolyl (9); 4-MeOPhS (10); 2- $\mathrm{NH}_{2} \mathrm{PhS}(\mathbf{1 1}), 5-\mathrm{NO}_{2} \mathrm{PyS}(\mathbf{1 2})$

1) Institute of Chemistry, FRC, Komi SC, Ural Branch, Russian Academy of Sciences, Syktyvkar, e-mail: gyrdymova-jw@chemi.komisc.ru; 2) Pasteur Research Institute of Epidemiology and Microbiology, St. Petersburg, Russia. Translated from Khimiya Prirodnykh Soedinenii, No. 6, November-December, 2019, pp. 1012-1014. Original article submitted April 17, 2019. 


\begin{tabular}{c|c|c|c}
\hline Compound & $\mathrm{CC}_{50}, \mu \mathrm{g} / \mathrm{mL}$ & $\mathrm{IC}_{50}, \mu \mathrm{g} / \mathrm{mL}$ & $\mathrm{SI}$ \\
\hline $\mathbf{1}$ & $85 \pm 6$ & $>300$ & 1 \\
$\mathbf{2}$ & $109 \pm 8$ & $50 \pm 7$ & 2 \\
$\mathbf{3}$ & $15 \pm 2$ & $>10$ & 1 \\
$\mathbf{4}$ & $>300$ & $300 \pm 0$ & 7 \\
$\mathbf{5}$ & $44 \pm 3$ & $6 \pm 1$ & 3 \\
$\mathbf{6}$ & $>300$ & $93 \pm 11$ & 21 \\
$\mathbf{7}$ & $>300$ & $14 \pm 2$ & 27 \\
$\mathbf{8}$ & $>300$ & $11 \pm 2$ & 6 \\
$\mathbf{9}$ & $283 \pm 16$ & $45 \pm 1$ & 2 \\
$\mathbf{1 0}$ & $>300$ & $123 \pm 14$ & 2 \\
$\mathbf{1 1}$ & $17 \pm 1$ & $>10$ & 6 \\
$\mathbf{1 2}$ & $51 \pm 4$ & $9 \pm 1$ & 32 \\
$\mathbf{1 3}$ & $>300$ & $9 \pm 2$ & 2 \\
Rimantadine & $19 \pm 1$ & $>10$ & 6 \\
\hline
\end{tabular}

$\overline{\mathrm{CC}_{50}}(\mu \mathrm{g} / \mathrm{mL})$ is the compound concentration causing 50\% cell death; $\mathrm{IC}_{50}(\mu \mathrm{g} / \mathrm{mL})$, concentration diminishing virus reproduction by $50 \%$; SI, selectivity index indicating preference for death of virus vs. normal cells, ratio of $\mathrm{CC}_{50}$ to $\mathrm{IC}_{50}$.

A comparison of analogous pairs of compounds with epoxycaryophyllane and hydroxycaryophyllene skeletons, i.e., thiols $\mathbf{3}$ and $\mathbf{4}$, sulfides 5 and $\mathbf{6}$, and symmetric disulfides $\mathbf{7}$ and $\mathbf{8}$ found that thiosesquiterpenoids $\mathbf{3}, \mathbf{5}$, and $\mathbf{7}$ with epoxycaryophyllane fragments were in most instances more active than their isomeric analogs $\mathbf{4}, \mathbf{6}$, and $\mathbf{8}$ with 5-hydroxycaryophyllene fragments. This was probably due to the greater reactivity of the epoxide ring in the tested molecules. Furthermore, symmetric disulfide 7 with an epoxide ring was slightly less cytotoxic than thiol $\mathbf{3}$ derived from it $\left(\mathrm{CC}_{50}>300\right.$ and 15, respectively). Their virus inhibitory concentrations were practically the same ( $\mathrm{IC}_{50} 14$ and $>10$, respectively). This could mean that the SH group was involved more in binding thiol $\mathbf{3}$ to cells, which was responsible for its increased toxicity as compared with oxidized derivative 7 in which the SH group was bonded to the same thioterpene fragment. The antiviral activity of bis-sulfides with ethylene (13) and vinylene linkers (14) was practically the same. However, the inhibitory activity of $\mathbf{1 3}$ was more selective for viruses so that its toxicity was significantly less than that of $\mathbf{1 4}$ with bis(alkylthio)ethene.

Considering both characteristics, the three most promising compounds of all tested sesquiterpenoids were symmetric disulfides $\mathbf{7}$ and $\mathbf{8}$ and 1,2-bis(4,5-epoxycaryophyllanylthio)ethane $\mathbf{1 3 .}$

The work used commercial (-)-caryophyllene oxide (1, Sigma-Aldrich). $(\{(1 R, 4 R, 6 R, 9 R, 10 S)-4,12,12$-Trimethyl-5oxatricyclo [8.2.0.04,6]dodec-9-yl $\}$ methyl)ethanethioate (2) [8]; $\{(1 R, 4 R, 6 R, 9 R, 10 S)-4,12,12$-trimethyl-5oxatricyclo[8.2.0.0 4,6$]$ dodec-9-yl\} methanethiol (3) [8]; (1S,2R,5S,9R,3Z)-4,11,11-trimethyl-8-(thiomethyl)bicyclo[7.2.0]undec3-en-5-ol (4) [9]; $(1 R, 4 R, 6 R, 9 R, 10 S)$-4,12,12-trimethyl-9-[(vinylthio)methyl]-5-oxatricyclo[8.2.0.0 $\left.0^{4,6}\right]$ dodecane $(\mathbf{5})[7,10]$; $(1 R, 5 S, 8 R, 9 S, Z)-4,11,11$-trimethyl-8-[(vinylthio)methyl]bicyclo[7.2.0]undec-3-en-5-ol (6) [7]; di( $\{(1 R, 4 R, 6 R, 9 R, 10 S)-4,12,12-$ trimethyl-5-oxatricyclo[8.2.0.0 $\left.{ }^{4.6}\right]$ dodec-9-yl $\}$ methyl)disulfide (22) [10]; $\operatorname{di}(\{(1 R, 5 S, 8 R, 9 S, Z)-5$-hydroxy-4,11,11trimethylbicyclo[7.2.0] undec-3-en-8-yl\} methyl)disulfide (8) [7], $(1 R, 4 R, 6 R, 9 R, 10 S)-9$ - $\{[($ benzimidazol- $1 H$ yl)disulfanyl]methyl $\}$-4,12,12-trimethyl-5-oxatricyclo[8.2.0.04,6]dodecane (9) [7]; $(1 R, 4 R, 6 R, 9 R, 10 S)-9$ - $\{[(4-$ methoxyphenyl)disulfanyl]methyl $\}-4,12,12$-trimethyl-5-oxatricyclo[8.2.0.0 4,6$]$ dodecane (10) [7]; $(1 R, 4 R, 6 R, 9 R, 10 S)-9-\{[(2-$ aminophenyl)disulfanyl]methyl $\}$-4,12,12-trimethyl-5-oxatricyclo[8.2.0.04.6]dodecane (11) [7]; $(1 R, 4 R, 6 R, 9 R, 10 S)-9$ $\{[(5$-nitropyridin-2-yl)disulfanyl]methyl $\}$-4,12,12-trimethyl-5-oxatricyclo[8.2.0.0 4,6$]$ dodecane $\quad(12) \quad[7]$; 1,2-bis $\left[\left(\left\{(1 R, 4 R, 6 R, 9 R, 10 S)-4,12,12\right.\right.\right.$-trimethyl-5-oxatricyclo[8.2.0.0 $\left.0^{4,6}\right]$ dodecan-9-yl $\}$ methyl)thio]ethane (13) [7]; and $Z$-1,2-bis $\left[\left(\left\{(1 R, 4 R, 6 R, 9 R, 10 S)-4,12,12\right.\right.\right.$-trimethyl-5-oxatricyclo[8.2.0.0 $\left.0^{4,6}\right]$ dodecan-9-yl $\}$ methyl)thio]ethene (14) [10] were prepared earlier. The synthetic methods and spectral characteristics of the compounds are given in the cited publications.

The work used MDCK cell line (spaniel kidney cells) and virus A/Puerto Rico/8/34 (H1N1) from the virus collection of Smorodintsev Research Institute of Influenza, Ministry of Health of Russia.

In vitro toxicity was assessed in tests on cell culture by preparing series of three-fold dilutions of the tested compounds at concentrations from 300 to $4 \mu \mathrm{g} / \mathrm{mL}$ in Eagle MEM growth medium. The diluted preparations were placed into plate wells. Cells were incubated for $48 \mathrm{~h}$ at $37^{\circ} \mathrm{C}$ in a $\mathrm{CO}_{2}$ incubator with $5 \% \mathrm{CO}_{2}$. Then, the MTT assay was performed in 96-well plates [11]. 
Cells were rinsed twice with normal saline $(0.9 \% \mathrm{NaCl})$ and treated with MTT [3-(4,5-dimethylthiazole-2)-2,5diphenyltetrazolium bromide] solution at a concentration of $0.5 \mu \mathrm{g} / \mathrm{mL}$ in MEM medium. Plates were incubated for $1 \mathrm{~h}$ at $37^{\circ} \mathrm{C}$, after which the liquid was removed and DMSO $(0.1 \mathrm{~mL})$ was added to the wells. Optical density of cells was measured at $540 \mathrm{~nm}$ on a spectrophotometer. The $\mathrm{CC}_{50}$ values, i.e., the compound concentration destroying $50 \%$ of the cells in the culture, were calculated from the results.

Direct antiviral activity of the compounds was determined by preparing series of tested compounds with serial dilutions from 300 to $4 \mu \mathrm{g} / \mathrm{mL}$ in growth medium and adding them to cell cultures $1 \mathrm{~h}$ before infection by the virus. Then, cells were infected with virus (moi 0.01) and incubated for $1 \mathrm{~h}$. The virus was removed. A fresh portion of compound was added. The plates were incubated for $24 \mathrm{~h}$, after which series of 10 -fold dilutions were made from the culture medium, placed into fresh cell culture, and incubated for $48 \mathrm{~h}$. Virus in wells was determined using hemagglutination reactions. For this, culture fluid was placed into plate wells for immunological reactions and treated with an equal volume of $1 \%$ chick erythrocytes in normal saline. The virus reproduction level in the plate wells was estimated from erythrocyte hemagglutination reactions. The virus titer was the inverse of the greatest virus dilution capable of giving a positive hemagglutination reaction and was expressed as the $50 \%$ infectious dose of virus in $0.2 \mathrm{~mL}\left(\log \mathrm{IC}_{50} / 0.2 \mathrm{~mL}\right)$.

Virus inhibitory activity was found from the reduction of the virus titer in the presence of the compounds as compared with the corresponding control wells without compounds. The $50 \%$ inhibitory concentration $\left(\mathrm{IC}_{50}\right)$, i.e., the compound concentration halving virus production as compared to the control, was calculated from the results. The selectivity index (SI), i.e., the ratio of $\mathrm{CC}_{50}$ to $\mathrm{IC}_{50}$, was calculated from the data for each virus.

Thus, $S$-containing derivatives of caryophyllene oxide could be considered promising substrates for designing compounds with antiviral activity.

\section{ACKNOWLEDGMENT}

The work was financially supported by the RFBR (Project No. 18-33-00846 mol_a).

\section{REFERENCES}

1. J. LeGoff, D. Rousset, G. Abou-Jaoud, A. Scemla, P. Ribaud, S. Mercier-Delarue, V. Caro, V. Enouf, F. Simon, J.-M. Molina, and S. van der Werf, PLoS One, 7 (8), e37095 (2012).

2. A. Pizzorno, Y. Abed, X. Bouhy, E. Beaulieu, C. Mallett, R. Russell, and G. Boivin, Antimicrob. Agents Chemother, 56 (3), 1208 (2012).

3. R. Trebbien, S. S. Pedersen, K. Vorborg, K. T. Franck, and T. K. Fischer, Euro Surveill., 22 (3), 30445 (2017).

4. O. S. Patrusheva, V. V. Zarubaev, A. A. Shtro, Y. R. Orshanskaya, S. A. Boldyrev, I. V. Ilyina, S. Y. Kurbakova, D. V. Korchagina, K. P. Volcho, and N. F. Salakhutdinov, Bioorg. Med. Chem., 24 (21), 5158 (2016).

5. A. S. Sokolova, O. I. Yarovaya, A. V. Shernyukov, Y. V. Gatilov, Y. V. Razumova, V. V. Zarubaev, T. S. Tretiak, A. G. Pokrovsky, O. I. Kiselev, and N. F. Salakhutdinov, Eur. J. Med. Chem., 105, 263 (2015).

6. O. I. Yarovaya, A. A. Shtro, Ya. R. Orshanskaya, V. V. Zarubaev, V. A. Khazanov, and N. F. Salakhutdinov, RU Pat. 2,616,255 C1, Apr. 13, 2017; Byull., No. 11, 1 (2017).

7. Yu. V. Gyrdymova, D. V. Sudarikov, O. G. Shevchenko, S. A. Rubtsova, P. A. Slepukhin, and A. V. Kutchin, Chem. Biodiversity, 14, e1700296 (2017).

8. Yu. V. Gyrdymova, D. V. Sudarikov, S. A. Rubtsova, P. A. Slepukhin, and A. V. Kutchin, Chem. Nat. Compd., 53, 463 (2017).

9. Yu. V. Gyrdymova, D. V. Sudarikov, S. A. Rubtsova, and A. V. Kutchin, Russ. J. Org. Chem., 53 (6), 853 (2017).

10. $\quad$ K. S. Rodygin, Yu. V. Gyrdymova, and V. V. Zarubaev, Mendeleev Commun., 27 (5), 476 (2017).

11. T. Mossman, J. Immunol. Methods, 65, 55 (1983). 